\title{
Hybrid control strategies of SVC for reactive power compensation
}

\author{
Mothanna Sh. Aziz, Ahmed G. Abdullah
}

Northern Technical University, Technical Engineering College, Iraq

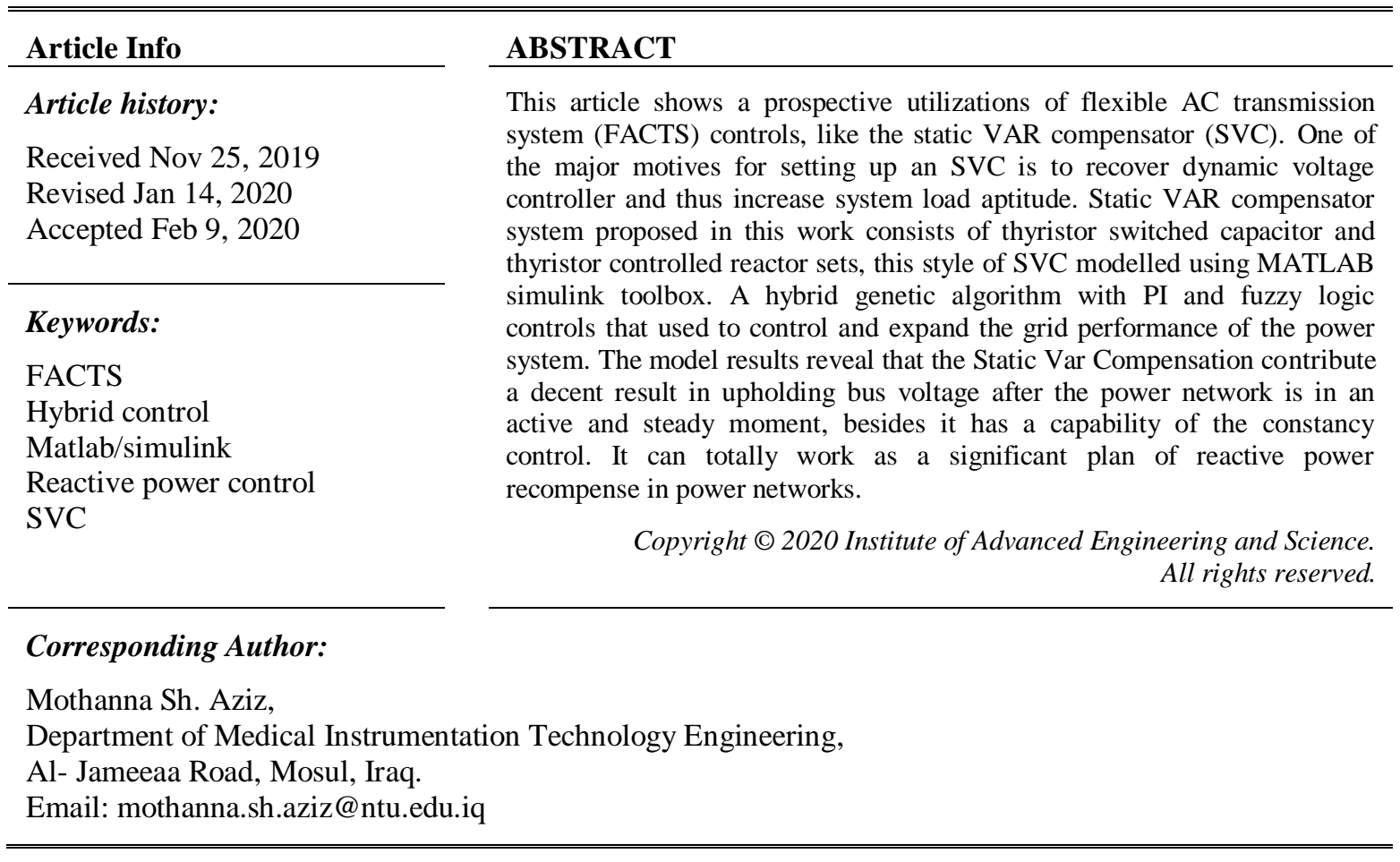

\section{INTRODUCTION}

The maximum thermal capacity of transmission circuits in power systems can be achieved by using flexible AC transmission systems technique that is based on controlled electronic devices [1]. Often, FACTS basically means the regulation of the three basic parameters that directly affect the transmitted AC power capacity that is voltage, impedance and phase angle [2,3]. As a result of the high demand for electrical power as well as the diversity of loads in the system with greater speed in changing the type of loads as well as the size of the load, disturbances in the electrical system increase. Therefore, active and reactive power values continuously changed, causing a change in the value of the power factor and thus the capacity of transmission lines. So it is important to find a way to stabilize the active and passive power value to optimum values using FACTS devices. Basically, SVC is a shunt FACTS recompense tool utilize thyristor as switch used for reactive reimbursement in the electrical network as source of a reactive power. SVC output can be regulated to exchange either capacitive or inductive currents to the connected system. This current is controlled to adjust specified parameters of the electrical power system usually bus voltage. The thyristor has been an essential component in understanding the SVC in addition to enable control of its reactive power [4]. It is operated either like a switch or as a nonstop monitored control valve thru adjusting the firing angle. It must be stated that the SVC current will have several harmonic content, a matter that requires consideration in the design operation. SVC is employed at a large number of systems over the world and is still assessed a desirable module to enhance the performance of AC power systems. Models of present SVC structure can be found in e.g. Finland and Norway [5, 6]. These systems were authorized to dampen inter-area swinging and to allow a power transfer, expand through a restricted device interface. The compensator is usually built from two main parts. The first contains a static reactor joined in series to a thyristor controlled reactor (TCR) built on bi-directional switches. The second part contains a permanent set of capacitors in parallel with 
the common resistance (TSC). A convenient controller used for turned on the thyristors to regulates the value of the current $[7,8]$.

One of the benefits of SVC formed by thyristor switching structures is that an infinite number of processes can be performed. Besides, the high accuracy of switching time also attained $[9,10]$. Thyristor is used as a valve for the connection of reactors, capacitors and additional devices connected to the electrical power system, which realizes the speed of the devices, without an electric arc, there is no impact switching effect and finally has an excellent performance [11]. Operating difficulties, as well as the flow current effect, can be significantly reduced if the switching time is efficiently controlled The dynamic response time is usually estimated between $0.01-0.02$ seconds. The TSC can monitor, track and give a quick and appropriate response to any possible change that occurs suddenly on the load simultaneously, also it can maintain the value of the power factor at the optimal value $[12,13]$. Improve dynamic reactive power, reduce voltage fluctuations and also increase power quality can be obtained as a result [14-16]. The literature is rich with various SVC techniques based on different topologies and with varying complexity. Afaneen A. Abood and her collages, 2012 proposed an SVC compensator was made up of an adaptive PID controller by using artificial neural networks (ANN). The MATLAB Simulink used to compare the two control methods, one of the (ANN-PID) controller and the other on (ANN) only. After obtaining the results from the two methods and comparing them together, it was concluded that the control method (ANN-PID) has a higher control ability, high reliability, and accuracy in the operation of the system in general [17]. Another study used the PI controller to check the necessary reactive power by connecting the capacitance and the reactance to the PCC (point of common coupling) with TSC and TCR respectively to enhance the power attribute in addition to the efficiency [18]. Other modified methods presented to resolve Multi-purpose complications to enable Optimized selection in electrical grids such as Galaxy based search algorithm (GbSA) where SVC exists to determine the finest power flow [4]. The GbSA algorithm used in the form of spiral arms for different galaxies to examine the best possible results. The proposed GbSA as well make use of the modified HillClimbing algorithm for local examination purposes. Based on the results obtained from a simulation, GbSA gave the best response to the optimal values or very close to them during all the running steps of the algorithm. Rajpoot, 2017 has proposed a controller based on the fuzzy logic technique, which was designed to obtain the best value of the firing angles for the Static Var Compensator so as to it could maintain voltage profile at flat state. The practical responses observed when a load voltage change for several various rates of load resistance, capacitance and inductance showed that the proposed controller system controls the regulation of the firing angles of the SVC system so that the receiving end voltage remains constant [2]. Adrian Pană and his team, 2018 introduced a mathematical model of a three-phase four-wire network based on resizing and simplifying the balancing reactive compensator, then changed it to a balanced capacitive compensator using resizing methods, and has the same functions. Depending on the theoretical and practical results observed, it was found that the unbalanced capacitive compensation can be equipped to fully compensate the positive sequence reactive power plus controlling load stabilizing in the three-phase four-wire system [9].

This paper describes a hybrid control technique using proportional, integral with genetic algorithm (PI/GA) and fuzzy logic with genetic algorithm (FL/GA) sachems connected to a static VAR compensator to improve electrical power transmission efficiency. The simulation can generate two different solutions for the control of the SVC system; one is the Pi / GA controller and the other one is FL/GA controller compared to other articles that uses one strategy to maintain the system's reactive power [19-21]. The following sections are organized as follows: Section 2 explains the methodology that used to implement the proposed technique. The simulation and results analyzing are evaluated and reviewed in Section 3. Section 4 presents the conclusion.

\section{METHOLODGY}

\subsection{TCR/TSC SVC model}

Schematic diagram of SVC is presented in Figure 1. Basically, the components that make up the compensator are divided into the following parts: thyristor switched capacitors, thyristor controlled reactor and finally harmonic filters. Also, shunt capacitors of the mechanical conversion type can be kept in operation and then it can be said that a fixed VAR system is applied. The harmonic filters used are capacitive at the fundamental frequency and are designed for harmonics created thru TCR. TSC value is usually smaller than that of TCR, so that control continuity is always achieved. Additional options can be adopted as thyristor switching reactors (TSRs) with static capacitors (FCs). Upon medium voltage, a consecrated transformer exists usually applied to the compensator scheme. In order to provide the necessary demand, the assessment of the SVC remains high. In addition to the capacitive reactive power and inductive reactivity, the rating may therefore be symmetric or asymmetric depending on the necessary demand. The rate might be set at 200 Mvar capacitive coupled with 200 Mvar inductive for instance or 200 Mvar capacitive besides 100 
Mvar inductive. SVC is very famously known for improving the quality of the power grid in general, particularly on the limits of stability of the static state, controlling the grid voltage, compensating for the dynamic VAR value at under-voltage and over-voltage, and also reducing the effect of sub-synchronous resonance and damp down the power oscillation $[2,6]$.

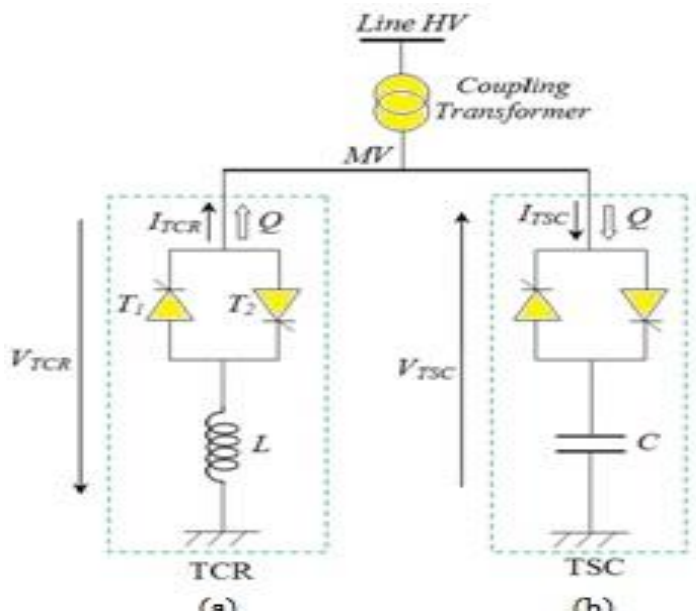

Figure 1. Schematic diagram of SVC

\subsection{V-I characteristics of SVC}

The adaptation of bus voltage for SVC along with SVC current as well reactive power. illustrated by steady state and dynamic characteristics of SVCs with a particular slope shown in Figure 2 [6].

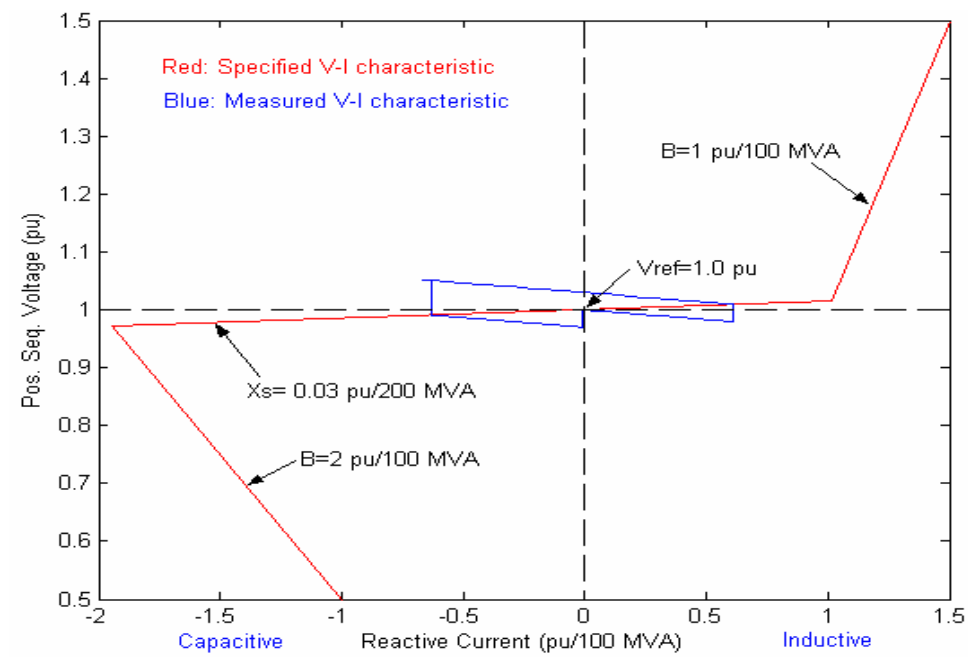

Figure 2. Characteristics of SVC

\subsection{Operation principle of SVC}

The thyristor control reactor can be described as a permanent reactor connected in series together with a Two-way thyristor switch. The level of TCR current be able to continually adjusted using adaptation of the thyristor firing angle from $90^{\circ}$ to $180^{\circ}$. In order to provide fast, accurate and smooth control of the system's interactive power source, the TCR firing angles be capable of completely regulated over single set of basic frequency. Thyristor switching capacitors can have two components: a series capacitor with a bidirectional thyristor switch and the other dampening reactor applied for switching capacitor banks on and off. 
The TSC is able to work in symmetry beside the TCR so as to the summation of the reactive power initiating by TSC and TCR remain linear [5, 6]. Figure 3 shows the SVC's single line diagram. Mainly, it consists of the following parts: a step down transformer, voltage controller estimating the susceptance value (B), the TCR element and the TSC group, as well as the distribution system which is responsible for determining the values of the firing angle $(\alpha)$ which operate and stop the TCR and TSC. Finally, the phaselocking loop (PLL) synchronizes the voltage in the secondary part [22, 23].

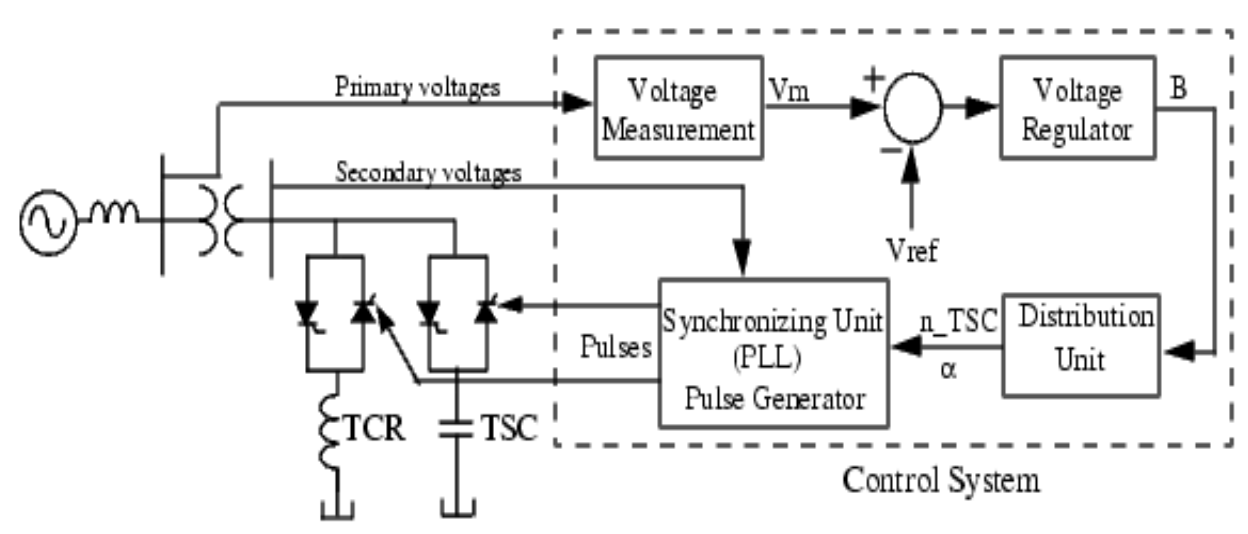

Figure 3. Single line diagram of SVC arrangement

\subsection{Modeling of SVC}

Simpower systems toolbox were used for the purpose of studying the features and descriptions of the SVC. In this work, a 300-Mvar static Var compensator arrangement that controls voltage at a 6000-MVA, $735-\mathrm{kV}$ power grid with $50 \mathrm{~Hz}$ frequency used $[2,24]$. The SVC presented be built from a $735 \mathrm{kV} / 16-\mathrm{kV}$, 333-MVA coupler transformer, single set of 109-Mvar thyristor-controlled Reactor (TCR) and three banks of 94-Mvar thyristor-switched capacitor (TSC1, TSC2, TSC3) connected to the transformer on the secondary side [25]. The simulation of SVC model presented in Figure 4.

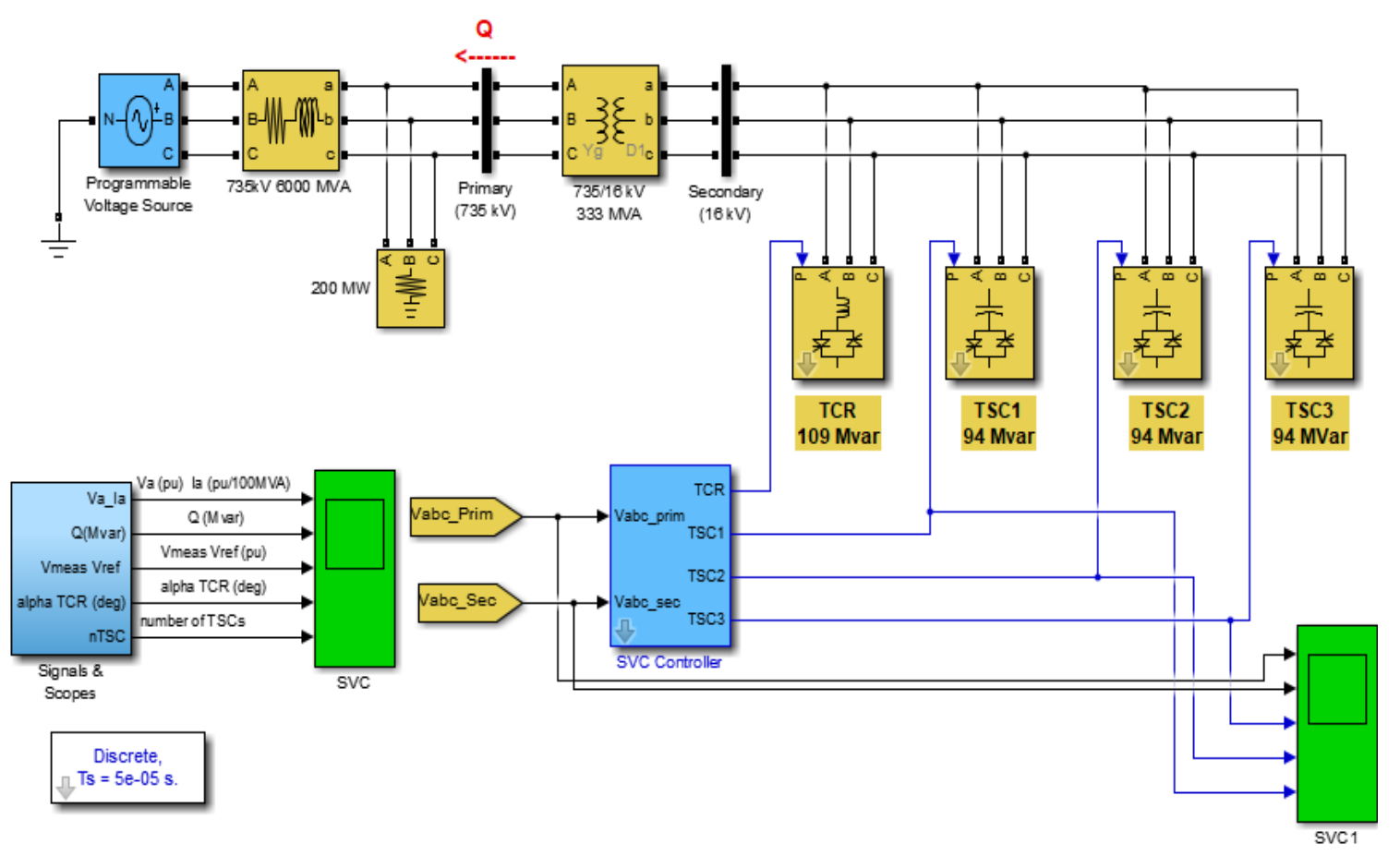

Figure 4. SVC Simulation model 


\subsection{Hybird control scheme of SVC}

To have the best performance of SVC for compensating reactive power in electrical network, a hybrid controller is proposed. Control of SVC means a fine and accurate manage of the time that SVC must interconnected to the network, how long its stay and finally, when the SVC must be pulled out of the power network. To do this, precisely thyristors firing angles must accurately controlled. Genetic algorithm used with proportional-integral technique in the first scheme and with a fuzzy logic controller in the second. The function of the GA in the first design is to evaluate the best values of KP, Ki gains, and in the second one, his function is to estimate the sufficient rules values for FL techniques After this step completed. Each strategy follows a different procedure to determine the active and accurate firing angle value required to operate the thyristors that responsible for connect and disconnect inductance and capacitances lines depending on the requirement of electrical network for active or reactive power injection to reach the steady and stable state. In this work, an SVC control scheme shown in Figure 5 used. Two strategies were followed for the control system design, Figure 6 shows the Simulink model of hybrid control technique proposed. The steps followed by the genetic algorithm to obtain the values of (Kp,Ki) when PI/GA control scheme used and the values of fuzzy memberships when using the fuzzy logic technique with genetic algorithm are detailed in the flow chart shown in Figure 7.

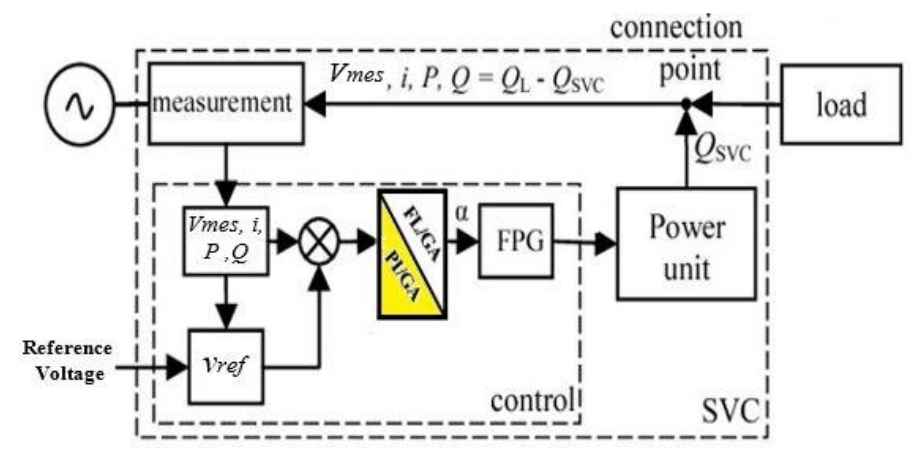

Figure 5. SVC Control scheme

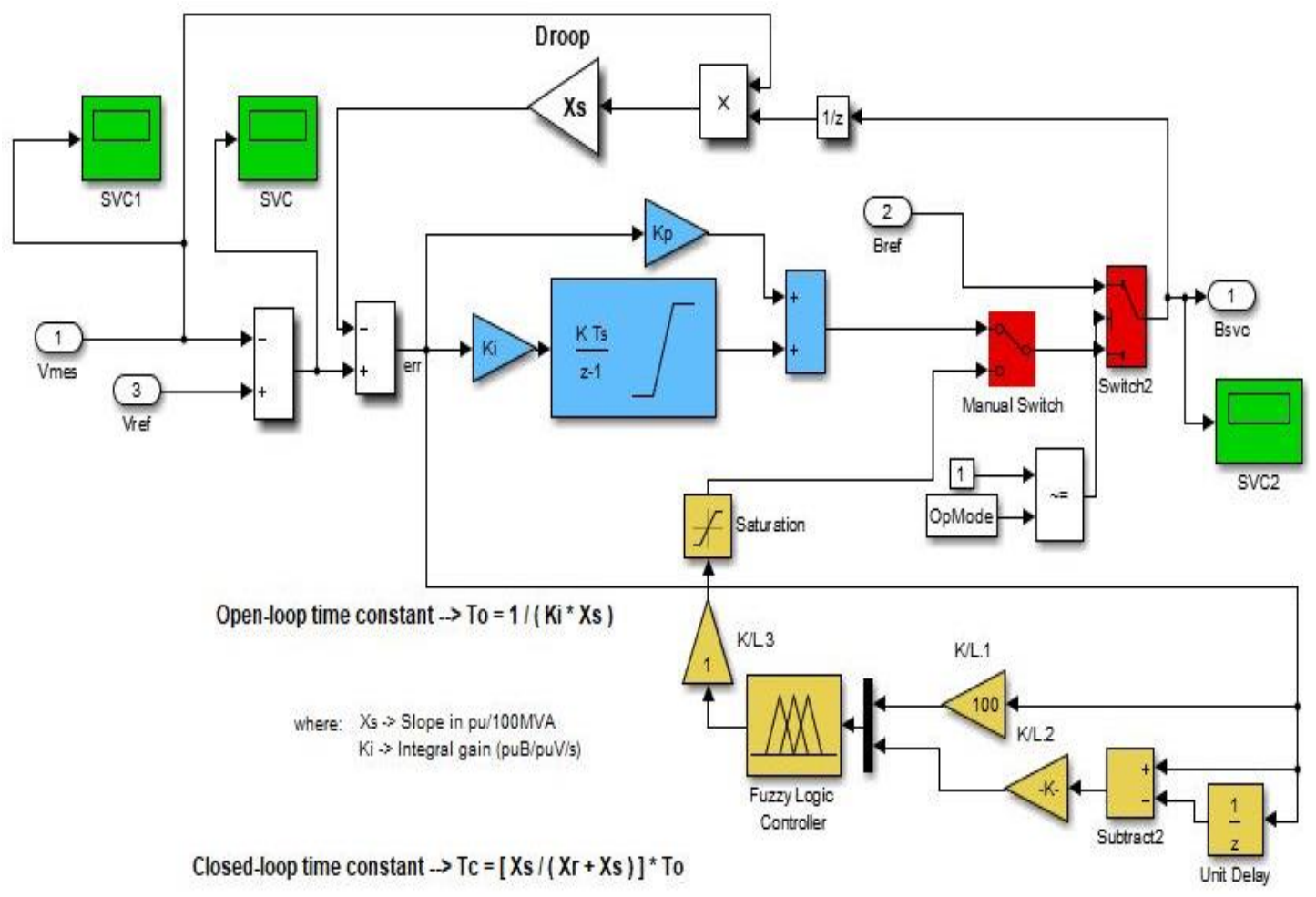

Figure 6. Simulink deign of hybrid control 


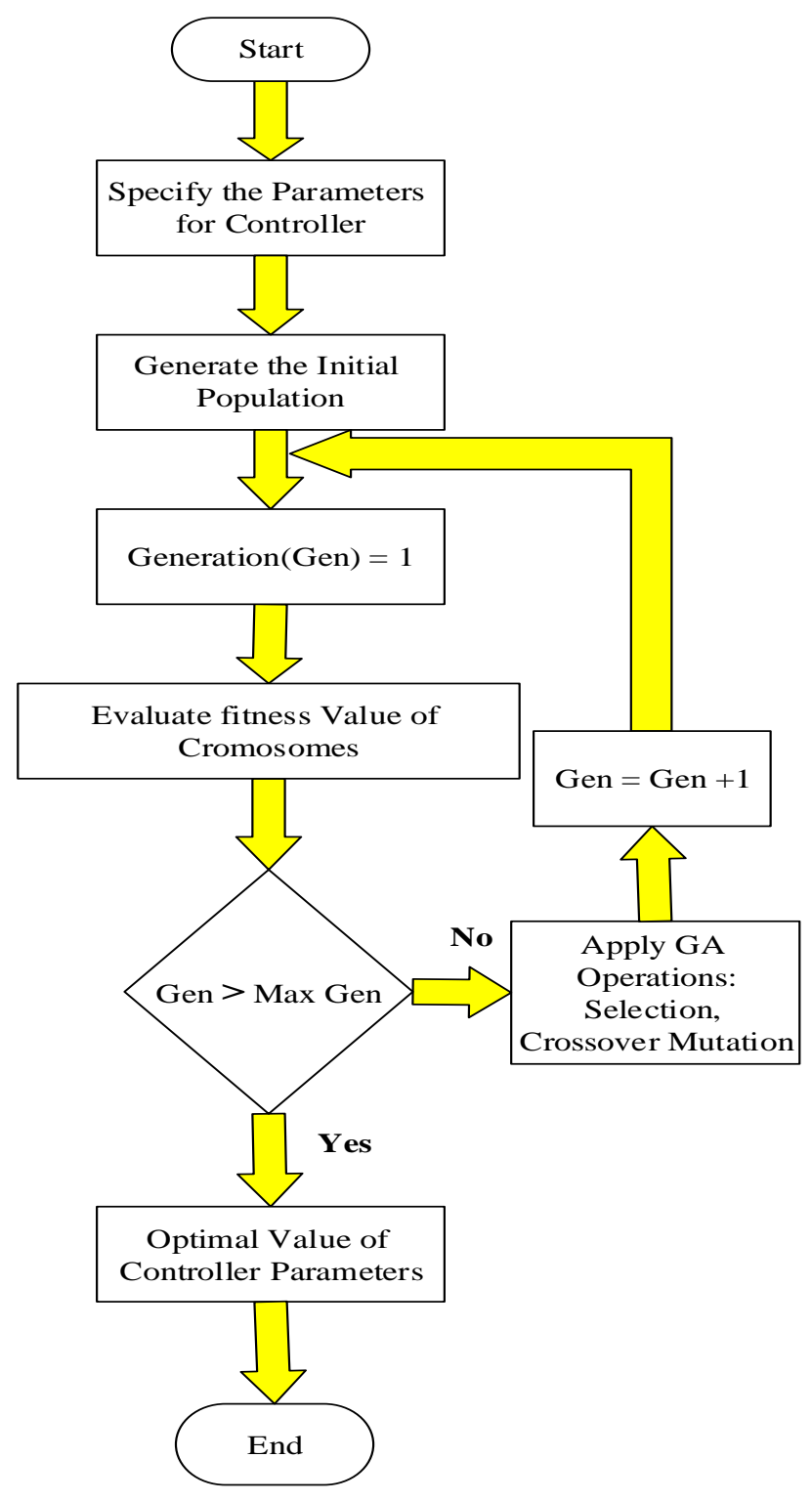

Figure 7. Flow chart of GA process

\section{SIMULATION AND RESULT ANALYSIS}

In this proposed work the system under study was simulated by the use of Matlab Simulink software, where the positive sequence voltage profile was monitored when using the SVC in the system, also, a three-stage programmable voltage source was used to generate specific voltage steps and the instantaneous dynamic response of the VAR compensator was observed for those changes in voltage. Now, the changes in the positive sequence voltage profile of the system will be analyzed using this model. The results from using $\mathrm{PI} / \mathrm{G}$ and FL/GA controllers compared together to clearly decide which one is faster, accurate and more reliable as SVC controlling scheme. Primarily the voltage supply is fixed on $1.004 \mathrm{pu}$, change in a $1.0 \mathrm{pu}$. Initially, Static Var Compensator is floating( zero current). This operating point can be attained when TSC1 is on and in operation and the TCR usually remains on maximum conduction $\left(\alpha=96^{\circ}\right)$. Then, Suddenly the voltages are reduced to $(0.97 \mathrm{pu}$ at $\mathrm{t}=0.2 \mathrm{~s})$, then increased to a higher value than the original value $(1.025 \mathrm{pu}$ at $\mathrm{t}=0.5 \mathrm{~s})$. Finally, the nominal voltage is restored to its value at $(1 \mathrm{pu}$ at $\mathrm{s} t=0.75)$ where the reactive power of the SVC compensator is reduced to zero, these steps are done by the $500 \mathrm{kV}$ three-phase programmable voltage source. Waveforms of $\mathrm{Va}(\mathrm{pu}), \mathrm{Ia}(\mathrm{pu}), \mathrm{Q}(\mathrm{pu})$, Vmeasured (pu), Alpha TCR(deg), and TSC numbers are shown in Figuress 8 and 9 for PI/GA and FL/GA control systems respectively. Based on the comparison between Figuress 8 and 9 curves show that using the FL/GA control algorithm give the best responds with time for voltage, current reactive power, firing angle and the number of TCS. Where the 
peak value of fault current smaller than case of PI/GA. As well, the change of Vmes(pu) peak value due to changes in supply voltage is smaller. Reactive power $\mathrm{Q}(\mathrm{pu})$ also has a better performance. In addition, the speed response of firing angle be more rapid than that of PI/GA and the number of TSCs required to absorb the same disturbance is less.

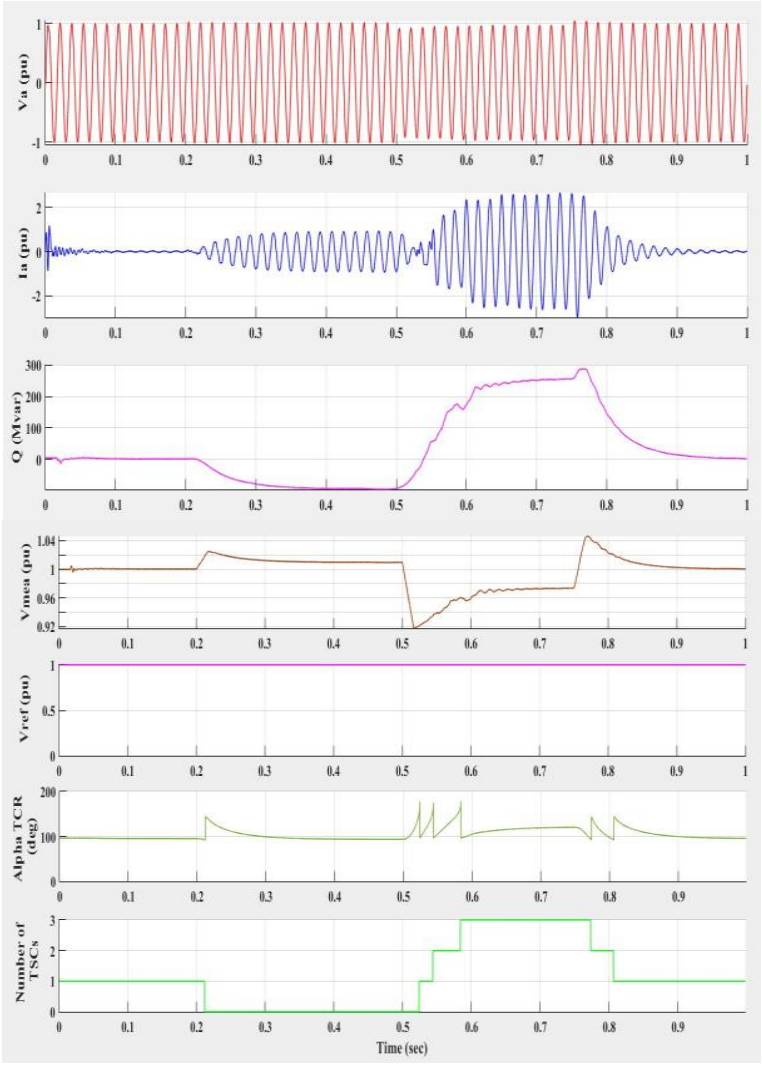

Figure 8. Simulation waveform of SVC using PI/GA Scheme
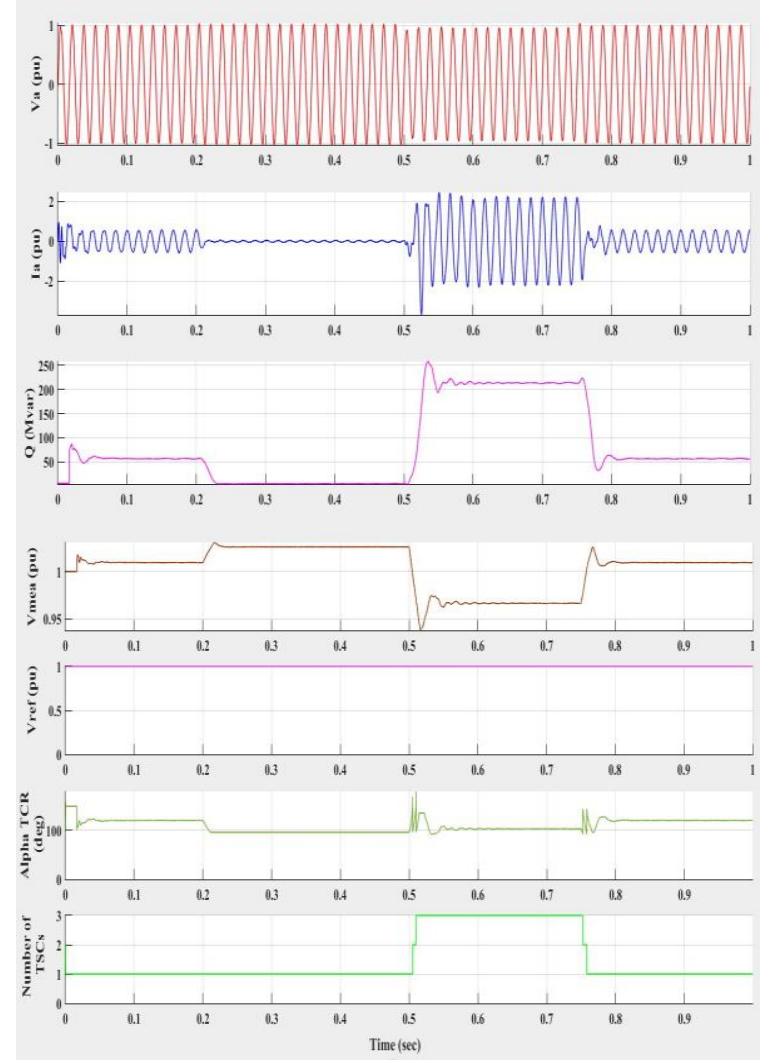

Figure 9. Simulation waveform of SVC using FL/GA Scheme

\section{CONCLUSION}

SVC can play an essential and influential role to improve the voltage characteristics of the electric power system. It can be summarized that the quality of power in the system can be greatly improved by using SVC. In this work, two different strategies were designed to optimize the optimum control of the firing angle for the SVC to obtain the best results, the first one using the genetic algorithm technique to proportional integral control and the second using the genetic algorithm with the fuzzy logic technique. By comparing the practical simulation results of all control methods, we note that the second method gave better results in terms of the response time of the SVC system for any sudden malfunction resulting in a change in the voltage of the power system. as well as the improvement of the system voltage and return it to the Steady state condition by injecting active and reactive power and thus improve the capacity of the system and recover the power factor as a result of it. As a final point the use of TCR-FC compensating scheme with FL/GA attending the drive of the firing angle control is a nonstop, active and reliable approach for governing reactive power.

\section{REFERENCES}

[1] C. H. S. Prakash, G. K. Rao, O. Chandrasekhar, and P. V Satyaramesh, "A Novel Multi-Functional DSTATCOM with Distribution Generation using FRC Controller," International Journal of Electrical and Computer Engineering (IJECE), vol. 8, no. 3, pp. 1373-1382, 2018.

[2] A. Mokhtari, F. Z. Gherbi, C. Mokhtar, and D. E. Kamel, "Study, analysis and simulation of a static compensator D-STATCOM for distribution systems of electric power," Leonardo Journal of Sciences ISSN 1583-0233, vol.25, no. 25, pp. 117-130, 2014. 
[3] S. C. Rajpoot, P. S. Rajpoot, K. Gupta, R. R. Yadav, and A. G. E. C. J, "Design Modeling and Simulation of Fuzzy Controlled Svc for Long Over Head Transmission Line," Journal of Electrical and Electronics Engineering (IOSRJEEE), vol. 12, no. 1, pp. 1-15, 2017.

[4] D. B. Kulkarni, S. Member, and G. R. Udupi, “ANN-Based SVC Switching at Distribution Level for MinimalInjected Harmonics," IEEE Transactions on Power Delivery, vol. 25, no. 3, pp. 1978-1985, 2010.

[5] K. Sindhu, B.T.Ramakrishna Rao, N. Gayatri, P.Balaji, "Modeling and Simulation of Static Var Compensator Controller for Improvement of Voltage Level in Transmission Lines," International Journal of Electrical and Electronics Research, vol. 3, no. 1, pp. 281-288, 2015.

[6] D. Danalakshmi, S. Bugata, and J. Kohila, "A control strategy on power quality improvement in consumer side using custom power device," Indonesian Journal of Electrical Engineering and Computer Science (IJEECS), vol. 15, no. 1, pp. 80-87, 2019.

[7] B. S. Kumar, M. Suryakalavathi, and G. V. N. Kumar, "Optimal Power Flow with Static VAR Compensator Using Galaxy based Search Algorithm to minimize Real Power Losses," Procedia - Procedia Computer Science, vol. 92, pp. 42-47, 2016.

[8] M. A. Kamarposhti, "Power Quality Compensation in Distribution System based on Instantaneous Power Theory and Recursive Fuzzy Proportional-Integral Controller," International Journal of Electrical and Computer Engineering (IJECE), vol. 8, no. 1, pp. 538-543, 2018.

[9] A. Pană, A. Băloi, and F. Molnar-matei, "From the Balancing Reactive Compensator to the Balancing Capacitive Compensator," www.mdpi.com/journal/energies, no. doi:10.3390/en11081979, 2018.

[10] T. Rajesh and S. Rajeswari, "Power quality improvement and reactive power compensation using enhanced sliding mode controller based shunt active power filter and static VAR compensator," International Journal of Engineering \& Technology, vol. 7, pp. 543-549, 2018.

[11] K. Shashikumar, C. Venkataseshaiah, and K. S. Sim, "Fuzzified Single Phase Automatic Sequential Reactive Power Compensation with Minimized Switches," TELKOMNIKA (Telecommunication, Computing, Electronics and Control), vol. 16, no. 2, pp. 889-899, 2018.

[12] S. Sagiroglu, I. Colak, and R. Bayindir, "Power factor correction technique based on artificial neural networks," Energy Conversion and Management, vol. 47, pp. 3204-3215, 2006.

[13] R. Bayindir, S. Sagiroglu, and I. Colak, "An intelligent power factor corrector for power system using artificial neural networks," Electric Power Systems Research, vol. 79, pp. 152-160, 2009.

[14] Y. Sun and L. Wei, "Simulation Analysis of Static VAR Compensator based on the Matlab/Simlink," Journal of Theoretical and Applied Information Technology, vol. 51, no. 2, pp. 240-244, 2013.

[15] F. L. Houari Boudjella, Fatima Zohra Gherbi, "Modelling and Simulation of Static Var Compensator (SVC) in Power System Studies by Matlab Houari," FASCICLE III, vol. 31, no. 1, pp. 76-82, 2008.

[16] M. J. Tahir, B. A. Bakar, M. Alam, and M. S. Mazlihum, "Optimal capacitor placement in a distribution system using ETAP software," Indonesian Journal of Electrical Engineering and Computer Science (IJEECS), vol. 15, no. 2, pp. 650-660, 2019.

[17] A. H. M. Abood, Afaneen A. Firas M. Tuaimah, "Modeling of SVC Controller based on Adaptive PID Controller using Neural Networks," International Journal of Computer Applications, 0975, vol. 59, no. 6, pp. 9-16, 2012.

[18] S. Park and K. Kim, "Efficient Power factor improvement with SVC based on the PI controller under Load Fault in the smart grid," International Journal of Applied Engineering Research ISSN, vol. 11. February 2016, pp. 96-100, 2016.

[19] V. Z. Manusov, P. V Matrenin, and N. Khasanzoda, "Swarm algorithms in dynamic optimization problem of reactive power compensation units control," International Journal of Electrical and Computer Engineering (IJECE), vol. 9, no. 5, pp. 3967-3974, 2019.

[20] A. Garg, "Voltage Profile Analysis in Power Transmission System based on STATCOM using Artificial Neural Network in MATLAB / SIMULINK," International Journal of Applied Information Systems, vol. 6, no. 1, pp. 7-15, 2013.

[21] M. A. Omran et al., "Comparisons of PI and ANN controllers for shunt HPF based on STF-PQ Algorithm under distorted grid voltage," International Journal of Power Electronics and Drive System, vol. 10, no. 3, pp. 1339-1346, 2019.

[22] A. Garg and S. K. Agarwal, "Modeling and Simulation of Static Var Compensator for Improvement of Voltage Stability in Power System," International Journal of Electronics Communication and Computer Engineering, vol. 2, no. 2, pp. 202-204, 2011.

[23] M. M. Karami and A. Itami, "Implementation of SVC based on grey theory and fuzzy logic to improve LVRT," Turkish Journal of Electrical Engineering \& Computer Sciences, vol. 25 no. 1, pp. 422-433, 2017.

[24] C. Science, S. A. Jumaat, I. Musirin, M. M. Baharun, and E. Engineering, "A Voltage Improvement of Transmission System Using Static Var Compensator Via Matlab / Simulink," Indonesian Journal of Electrical Engineering and Computer Science (IJEECS), vol. 6, no. 2, pp. 330-337, 2017.

[25] M. Sreerama, K. Prakasam, M. Suryakalavathi, and B. R. Reddy, "Design, Modeling and Simulation of Fuzzy Controlled SVC for Transmission Line," International Journal of Engineering Science Invention, vol. 2, no. 3, pp. 9-18, 2013. 


\section{BIOGRAPHIES OF AUTHORS}

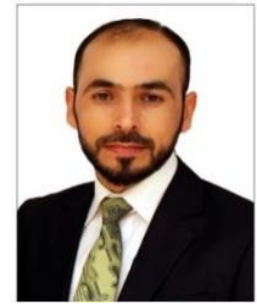

Mothanna Sh. Aziz. I am an electrical engineer, I have two degrees in electrical power engineering BEng.in 2005 and MEng in 2008 from Northern Technical University/Iraq. Currently, I am an assistant lecturer in Northern Technical University with full time position. I am interested in research area related to power electronic, electrical power systems engineering and control.

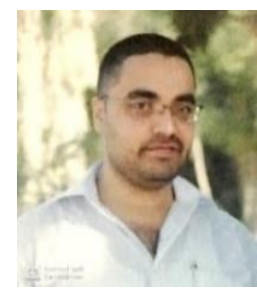

Ahmed G. Abdullah. I am an electrical engineer, I have two degrees in electrical power engineering BEng.in 2005 and MEng in 2009 from Northern Technical University/Iraq. Currently, I am an assistant lecturer in Northern Technical University with full time position. my research area focused on power electronic, control and renewable energy systems. 